\title{
Pay (Be)fore Performance: The Signing Bonus as an Incentive Device
}

\author{
Edward D Van Wesep \\ Kenan-Flagler Business School \\ University of North Carolina
}

March 2008

\begin{abstract}
This paper investigates the use of a signing bonus as a tool for firms to signal their quality to prospective employees. It is the first to provide a theoretical basis for the signing bonus, one of the most common elements of compensation packages for white collar employees. It also shows that low performance incentives can serve a complementary purpose, implying that within a job/industry pair we should expect higher quality firms to employ higher signing bonuses and lower performance pay. This runs contrary to previous literature relating firm quality to incentive intensity and calls into question the use by empiricists of low performance pay as an indicator of poor corporate governance. The paper makes a number of empirically testable predictions and provides precise guidance on how modelling techniques will affect parameter estimates. In particular, the inclusion of job/industry fixed effects in regressions of signing bonus size or incentive intensity on relevant exogenous variables will reverse the signs of parameter estimates.
\end{abstract}

\section{Introduction}

The signing bonus has become a ubiquitous feature of high level white collar contracts and traditional explanations from the business community of why this is the case, when scrutinized under an economic lens, tend to disappoint. The signing bonus is the antithesis of incentive pay: after all, a new hire can simply take the bonus and immediately leave the firm. ${ }^{1}$ While economists have paid significant attention to other contract elements that appear to run against the "pay for performance" paradigm- severance pay, for example- ${ }^{2}$ there has been

\footnotetext{
${ }^{1}$ There are often restrictions that if the worker leaves the firm within one year the worker must pay back a pro-rated fraction of the bonus, but in practice this may be ignored. The only way for a firm to recover that amount is a lawsuit, which may generate ill will, bad press, a countersuit or be just plain expensive.

${ }^{2}$ For examples of severance pay in optimal contracts, see Manso (2008), Almazan and Suarez (2003), Lambert and Lacrker (1985) or Van Wesep (2008a).
} 
no academic attention paid to the equally perplexing signing bonus. Arguments from the business community for why we see signing bonuses typically mistake arguments for more pay in general as arguments for signing bonuses in particular. For example, "we are luring a employee who is losing rights to unvested stock or options and therefore must make the employee whole" is more a story about what the firm must pay, not when. The most plausible of the common arguments for signing bonuses is that they relieve credit constraints: graduating students often need cash now rather than later, and other employees may have time between the last paycheck at the firm they are leaving and the first at the new firm.

These arguments get the timing right, but miss an important fact. Rather than offer a signing bonus, the firm could offer a "signing loan" at $0 \%$ interest, repaid over the course of the year. This structure would lead to the same time series of cash flows, but minimize the risk of a signing bonus by making it more recoverable if a employee leaves the firm early: rather than having to sue the employee for a pro-rated share of the bonus, the firm could just threaten to charge off the debt. This would entail little cost for the firm, offer considerable penalty for the employee, and solve the credit constraint problem in one fell swoop. This practice exists at some firms, but usually in addition to a signing bonus rather than in lieu of one. We are left with a mystery that the finance and economics literature has simply not addressed.

So far as I know, there is no previously described theoretical basis for the signing bonus, ${ }^{3}$ one of the most prevalent and sought-after contracting features in industry today. This paper provides a justification that makes intuitive sense: the bonus is a way for high quality firms to differentiate themselves from low quality firms, attract the best employees and induce them to work hard. Because the signing bonus is paid before a employee joins the firm and precisely because employees can depart the firm after only a brief stay, a signing bonus is a much less expensive contracting tool for a firm that is confident that a employee will like what she sees once she joins the firm than it is for other firms. Much like advertising can be a signal of product quality, ${ }^{4}$ a signing bonus can be a signal of firm quality.

The model here also presents a novel relationship between incentive intensity and firm quality. Two prominent theories of this relationship are the corporate governance view and the Milgrom and Roberts (1992) view. The former argues that better governed firms, all else equal, will have both higher marginal productivity and more intense incentives. There should therefore be a positive relationship between quality and incentives, and weak incentives may be taken as an indicator of weak governance. The latter view states that the incentive intensity, as measured by the fraction of the value of the marginal product retained by the employee, should be constant across firms of differing quality. The model below suggests a negative relationship and is, as far as I know, the first to do so. This model suggests, therefore, that contrary to the Bebchuck and

\footnotetext{
${ }^{3}$ The claim that there is no previous theoretical basis for signing bonuses naturally excludes the few attempts that do not withstand economic scrutiny.

${ }^{4}$ See Milgrom and Roberts (1986)
} 
Fried (2004) view that strong incentives imply a better firm, the relationship might be quite the opposite. To be clear, the model predicts that the fraction of marginal value retained by the employee is decreasing in firm quality but the total size of the performance bonus is higher at higher quality firms: employees choose to exert higher effort at higher quality firms and those efforts are, by definition, more productive.

This paper investigates the relationship between compensation elements (wages, performance incentives and signing bonuses), firm quality and information availability. The model is a simplification of the following general story. employees are offered contracts and can choose whether to join the offering firm. If they join they potentially receive a signing bonus and a regular paycheck. For a number of reasons the employee may not want to stay with the firm: perhaps her colleagues are dull, perhaps there is too much work, perhaps she is being paid on commission and finds that the firm's resources will lead to low sales. For these and many other reasons, the employee may choose to leave the firm. If she leaves, she has been paid a wage for time put in, but regardless of that time she can keep the signing bonus. The rate at which the employee learns about her firm is the "quality of information" in the job or industry.

This story does not immediately reveal any relationship between the signing bonus and performance incentives, yet there is an underlying relationship. There will be many industries and job titles where neither type of bonus will be offered: when employee type or effort is observable there is no need for performance bonuses and no justification for signing bonuses. For other job types or industries there will be both types of bonus, so we should see a positive relationship between whether each type of bonus is offered in a compensation package.

Within a job/industry pair in which bonuses are offered, however, we will see a negative relationship between firm quality and incentive intensity combined with a positive relationship between firm quality and signing bonus size. More productive firms offer larger signing bonuses and offer lower performance incentives. Furthermore, within a job/industry pair higher signing bonuses are associated with lower quality information and higher dispersion of firm quality within the industry, ${ }^{5}$ while incentive intensity is increasing in information quality and decreasing in firm quality dispersion. To restate: the existence of each type of bonus is positively correlated, but the size of the bonuses within a job/industry pair is negatively correlated. Empiricists researching these compensation features must design studies accordingly by controlling for job/industry fixed effects.

These findings yield a plethora of testable predictions both cross sectionally (the comparative statics mentioned above) and over time. As employees' outside options and firm productivity adjust due to macroeconomic shocks, the prevalence and size of signing bonuses should change: they should be more common and larger in booms. I believe that the predictions from the model correspond

\footnotetext{
${ }^{5}$ Dispersion in firm quality is the ratio of the value of the marginal product at the highest productivity firm to the value of the marginal product at the lowest
} 
well to stylized facts and that the theory is immediately intuitive and attractive. Section 2 motivates the discussion with some stylized facts about signing bonuses and a discussion of the literature. Section 3 describes the model and provides motivating examples for the cases where there is either full information regarding firm quality or no information. Section 4 derives equations for the optimal compensation scheme for firms of each quality level under varying information precision. Section 5 analyses the results and provides a discussion of empirical implications. Section 6 describes the previously discussed alternative to the signing bonus: the signing loan. It also shows why this model justifies the bonus instead of the loan while other stories cannot. Section 7 concludes. Unless otherwise shown, proofs can be found in the appendix.

\section{Stylized facts and the literature}

Before delving into the model it is worth discussing some stylized facts surrounding the use and size of signing bonuses. This paper shows that the incidence and size of signing bonuses depends primarily on three factors: the rate at which employees can learn about the quality of the firm at which they work, the dispersion of firm quality within a job/industry, and the quality of the firm itself. It is important to check the relationship of these predictions with good data, but those data are hard to find.

Data from large government surveys typically do not include information about signing bonuses and are not particularly detailed regarding the timing and conditionality of pay. Even precision resources like ExecuComp do not separately break out signing bonuses from other pay elements like severance pay, debt forgiveness and tax reimbursements, to name a few; furthermore, the theory in this paper is relevant for any job, not just executive positions, so focused resources like ExecuComp would significantly limit the analysis. Some compensation consultants collect this information, but only sporadically and not necessarily with the specifics that appeal to an academic researcher. Nonetheless, to the extent that this information is available, it is displayed in the five figures discussed below, provided courtesy of []. There are certainly other "facts" that seem apparent to people in industry and academia and it is worth laying those out here before moving on.

Within an industry it is typical for certain types of job to be associated with signing bonuses: they are primarily awarded to those in high human capital positions. Figure 1 confirms this intuition by plotting the fraction of firms offering a signing bonus to at least one employee of a particular job class. That fraction is close to unity for executives and technical managers and professionals. It is middling for sales and operations personnel and low for hourly employees. Figure 3 shows that the prevalence of the signing bonus as a pay practice and the typical size of the package tend to go together: higher frequency of signing bonuses is associated with higher bonuses when they are awarded (though sales managers are an anomaly). 
Across industries it seems that those with high levels of firm specific intellectual capital and those employing employees with high human capital are more prone to giving signing bonuses and also more prone to give performance pay. It is unusual to see signing bonuses without some significant performance pay: it may come in the form of a performance bonus, an intense "up or out" retention policy wherein even mediocre performers are typically fired, or a rapid increase in outside options and pay for employees who distinguish themselves. In any of these situations performance is highly rewarded and in most firms with this performance-pay relationship a signing bonus is apparently a must.

Whether signing bonuses are offered at better or worse firms is difficult to determine formally without some measure of firm quality, but it accords with casual observation that elite companies hiring elite individuals offer signing bonuses. They are a contract feature at all top management and litigation consultants, corporate law partnerships, and banks. Within each of these industries, however, it is unclear from casual observation whether the incidence and size of signing bonuses depend on relative firm quality. The theory in section 4 suggests that in industries like these all elite firms may offer signing bonuses and performance pay at similar levels, and this may or may not conform to the reader's knowledge or expectations.

Most signing bonuses are awarded by the time of the first paycheck, as figure 4 shows, and even those paid later are typically paid within one or two quarters (it is admittedly difficult to call a bonus a "signing bonus" if it is paid later than that) as shown in figure 5. These figures confirm that a signing bonus is a serious commitment by a firm to a employee: when employee can easily abscond with the bonus it is a risk for the firm to offer it. Furthermore, figure 5 shows that most bonuses are not large enough for it to be worth the firm's while to attempt to recover lost bonuses via a lawsuit. These facts are critical to the model below.

This paper argues for a non-monotonic relationship between firm quality and incentive intensity: within a job/industry pair, incentives would be weaker at the higher quality firms but across industries and jobs it is likely that firm quality and incentive intensity would be positively related. There are no stylized facts that I know of relating firm quality and incentive intensity: indeed, one previously used measure of firm quality (or the quality of corporate governance at least) is incentive intensity. This paper suggests that this measure may not be appropriate. It certainly seems that firms like Goldman Sachs or top hedge funds reward employees richly for success, but the measure of incentive intensity used in this paper is the fraction of the marginal product retained by the employee. The model proposed below says that, within an industry, this fraction is decreasing in firm quality even though total performance based pay is higher at higher quality firms. ${ }^{6}$

It is worth supporting these broad arguments with some basic facts about industry attributes and compensation practices in a variety of jobs and indus-

\footnotetext{
${ }^{6}$ Employees work harder at these firms and their marginal product is higher so their pay can increase in firm quality even if the ratio of that pay to total production is decreasing
} 
tries:

1. Professor: No signing bonus, low incentive pay. With tenure, professors have some of the lowest incentive pay among all professions though of course pay does increase for highly productive faculty. It is easy for a potential hire to have a good idea of how productive she will be at a particular school. There is moderate dispersion in school quality (with quality defined as in this paper) and it is relatively easy to monitor a professor's skill and effort.

2. Waiter: No signing bonus, low incentive pay. It is not difficult for a potential hire to predict her productivity at a restaurant: a glance at the menu and a couple visits during the week suffice. There is moderate dispersion in restaurant quality within a particular class of restaurant. It is easy to monitor a waiter's skill and effort.

3. Employee \#6 at a high-tech start-up: High signing bonus (stock options), high incentive pay. It is very difficult for a potential hire to predict her productivity at the firm. There is very large dispersion in firm quality. It is moderately difficult to monitor a employee's skill and effort.

4. Management consultant: Moderate signing bonus, high incentive pay. It is difficult for a potential hire to predict her productivity at the firm. There is high dispersion in firm quality. It is difficult to monitor a employee's skill and effort.

5. CEO: High signing bonus, low to moderate incentive pay. It is very difficult for a employee to predict her productivity at the firm and there is a very large dispersion in firm quality. It is very difficult to measure a employee's skill and effort.

These observations can be compiled as shown in table 1. Each profession is assigned a rank among the five shown here in each of four categories. "Signing bonus size" and "incentive intensity" describe the contract while "quality observability" describes the information availability regarding firms in each industry and "quality dispersion" describes how different a typical employee's productivity would be at higher and lower quality firms within the industry. "employee observability" describes the ease with which the firm can monitor the employee's effort and observe the employee's skill.

This chart is not scientific and the reader might take issue with particular rankings or prefer the inclusion of different professions; the chart is simply a back of the envelope attempt to put numbers to parameters and contract terms found in the model below for a variety of professions. Table 1 provides some suggestive predictions we should look for in a theory. First, signing bonus size is strongly related to the information availability in a job/industry. For job types and industries where firm quality is easily observable there are fewer and smaller signing bonuses. Furthermore, as quality dispersion increases within 
an industry, signing bonuses rise. The relationship between incentive intensity and the parameters is more complicated. It appears that quality observability and quality dispersion are negatively related to incentive intensity, but it seems that once effort observability is considered the effect is removed. The necessity of incentives when effort is unobservable is a classic aspect of contract theory and the "information" in figure 6 seems to support it.

It is worth discussing the literature on signing bonuses and incentive intensity. The economic literature on signing bonuses is virtually nonexistent. Most work is concerned with sports economics and the NFL in particular, which is known for very large signing bonuses. The justification for these bonuses is unique and not present in other industries: according to union contracting rules, a team can cancel a player's contract at will and not owe the player severance pay nor any lost future earnings. Major League Baseball, in contrast, requires that teams pay players the entire amount due upon dismissal. Not surprisingly, baseball does not feature large signing bonuses while football does. ${ }^{7}$

One paper attempting a theory is Arya, Frimor and Mittendorf (2003), in which sunk costs are a way of committing the firm to a course of action that induces employees to acquire firm specific human capital. By paying the employee in advance the firm reduces future hiring costs and the employee can be more confident of his hiring. Their paper relies on signing bonuses being paid well before the employee joins the firm (in fact, before the employee even begins her education or training). It would be rare to find this type of bonus in practice, as figure 4 shows: the model does not fit the facts and a fresh look is warranted.

The literature on incentive intensity is much richer. Holmstrom (1979) and Milgrom and Roberts (1992) provide basic theoretical underpinnings relating incentive intensity to employee productivity, risk aversion, costliness of effort and the observability of effort. This has been significantly extended in a large number of directions including incentive intensity for teamwork (Holmstrom (1982) ) and the provision of incentives through tournaments rather than explicit contracts (Lazear and Rosen (1981) and Green and Stokey (1983)). The literature is too large to describe here, but see Prendergast (1999) for an excellent review and comparison of theory to evidence.

So far as I know there has not been a theory establishing a negative link between firm quality, defined as the value marginal product of employee effort, and incentive intensity that predicts a negative or non-monotonic relationship between the two. Milgrom and Roberts (1992) predict that incentive intensity is constant in firm quality ${ }^{8}$ and governance theories like Bebchuck and Fried

\footnotetext{
${ }^{7}$ The actual contracting rules are more complex and in football also concern the way different forms of pay affect the salary cap, but the largest factor driving signing bonus differences is the variation in "right to fire" rules.

${ }^{8}$ In particular their "incentive intensity principle" argues that incentive intensity $\beta=$ $\frac{\pi^{\prime}(e)}{c^{\prime}(e)+\gamma \sigma}$ where $\pi^{\prime}(e)$ is the marginal revenue from effort, $c^{\prime}(e)$ is the marginal cost of effort (borne by the worker), $\gamma$ is the worker's coefficient of risk aversion and $\sigma$ is a measure of how well effort can be measured. $\beta$ is measured in dollars per unit output. If output $z$ can be sold at price $p$ then $\pi^{\prime}(e)=p z^{\prime}(e)$. Applying typical regularity conditions, the variable $e$ can
} 
(2004) predict a positive relationship. The model presented her predicts a nonmonotonic relationship where a simple regression of incentive intensity on firm quality measures would find a positive relationship but including job/industry fixed effects would force a negative relationship. That higher quality firms would use weaker incentives is novel and not intuitive but is a clear result of the succeeding model.

To begin the analysis it is worth considering two simple examples that highlight the results of the paper with little complexity. We consider in turn a model of contracting under complete information and one of contracting under no information and derive relationships between information, firm quality, industry quality dispersion and equilibrium contract structure.

\section{A pair of simple motivating examples}

The model presented in this paper is a stylized version of a simple fact: employees do not always know exactly they will like a new job and can always choose to quit if it does not go well. Firms that offer wages solve this most simply by only paying employees for time spent working. When employees must be screened for quality or induced through incentives to work hard, an end of year performance bonus is common. In this case, the longer a employee works at a firm prior to the performance bonus being paid, the less likely she is to leave: indeed, it is common in industries like law, banking and consulting for employees to leave the firm immediately after the payment of performance bonuses. Given that hiring and training are costly activities, an end of year bonus serves a dual role of improving employee retention later in the year. A employee, on the other hand, can practically, if not legally, abscond with a signing bonus soon after beginning her employment. This is also the time when she likely learns most about the quality of, and her fit with, the firm.

A simple model of this allows the employee to leave immediately after the start of her employment, especially because if a performance bonus is present she would be unlikely, in practice, to leave as the year progresses. The basic model is as follows:

1. A firm of hidden quality $z_{i}$ offers a take-it-or-leave-it (TIOLI) contract to a employee of hidden quality $\theta_{j}$, which includes a wage $w$, performance bonus rate $\beta$, and signing bonus $S$. The employee can either accept or reject this offer. If the employee rejects the offer the game ends and payoffs are 0 to the firm and $u(\theta)$ to the employee.

be defined so that either marginal product or marginal cost is constant at 1 . We can do that with marginal product to get $z^{\prime}(e)=1$. Then dividing each side of our preceding equation by $p$ we get $\frac{\beta}{p}=\frac{1}{c^{\prime}(e)+\gamma \sigma}$. The left hand side of this equation describes the fraction of the value marginal product retained by the worker, which is how incentive intensity is defined in this paper. One can see that this is constant in firm productivity, which is measured by $p$. 
2. If the offer is accepted, the employee sees a signal of the quality of the firm $\widehat{z}$. The employee can now once again stay or leave. If the employee leaves she receives $S+u(\theta)$ and the firm receives $-S$. The signing bonus is paid regardless of the employee's choice but her reservation utility is unchanged.

3. If the employee stays she exerts hidden effort $e$. Payoffs are then $\pi=$ $(1-\beta) \theta z e-S-w$ to the firm and $S+w+\beta \theta z e-c(e ; \theta)$ to the employee. That is, total production is $\theta z e$. The firm pays the employee her wage, her signing bonus and a share of the production and retains the difference. The employee receives her pay but bears a cost of her effort. Note that ex post, firm type is known to the employee.

There are a few points to be made regarding this model. First, there is no risk in the productive technology. This will relieve us of many complications that do not add to the insights of the model like the limited liability constraint, risk aversion of the agent, integrals and conditional expectations. Second all bargaining power belongs to the firm which makes TIOLI offers to the employee. As is standard, however, employee beliefs can generate many contracting equilibria that are sub-optimal (in a global sense) for the firm.

Third, the contract offer comes before the signal. The idea here is that firms offer a contract and, if accepted, the employee joins the firm. After some time at the firm, perhaps a short time, the employee can observe some noisy signal of the firm's quality and quit if she feels she is wasting her time. In practice, this may be after a week, a month, a quarter, or a year. For expositional simplicity, the assumption here is that the employee observes this signal before the "first paycheck" is paid and that there is no updating of this signal within the period. This is a strong assumption but it captures the real dynamics with some accuracy while setting the highest bar against signing bonuses.

Fourth, we are restricting interest to linear contracts. Considering that there is no risk, a contract only actually needs to do two things. It must target a particular effort level on the part of a employee and it must make sure that no other effort choice is better. The linear contract specified above can achieve this as well as any other contract form given that there is no risk. A linear contract also makes more sense for the employee. If the signal is not perfectly informative then the employee does not know for certain what sort of firm it is working for. Contracts that feature payments that are complex or highly responsive to output level could be perceived by employees are "risky" in the sense that they can not know with certainty what output will be. Linear contracting here does not reduce the set of equilibria and is certainly more realistic.

We will make some assumptions before continuing:

A1: $\theta=1$.

A2: $c(e ; \theta)=\frac{1}{2} e^{2}$.

A3: $z \in\left\{z_{L}, z_{H}\right\}$ with fraction $\gamma$ of type $z_{H}$. Also, $z_{H}>z_{L}$.

A4: $\widehat{z}=H$ with probability 1 if $z=z_{H}$ and $\widehat{z}=H$ with probability $1-p \leq 1$ and $\widehat{z}=L$ with probability $p \geq 0$ for $z=z_{L}$. 


$$
\text { A5: } z_{L}=1
$$

Assumption A1 relieves us of solving for optimal screening contracts on behalf of the firm. While this type of question is no doubt interesting, it is beyond the scope of this paper. Assumption A2 defines a simple cost of effort function that will greatly simplify what would otherwise become a rather nasty analysis. Importantly, it is convex and will yield effort as a linear function of incentive intensity and firm quality. A3 reduces the set of firm types to two, which is a significant mathematical restriction that certainly affects results. A4 states that the probability of a low type firm being revealed by the signal $\widehat{z}$ is $p$ which may be positive. A5 normalizes the low quality firm's marginal product to unity. We can then think of $z_{H}$ as measuring the dispersion in firm quality within the job/industry pair rather than the actual technology of the high quality firm: $z_{H}=\frac{z_{H}}{z_{L}}$.

Armed with these assumptions we will now solve the game in two extreme situations. First we will assume that $p=1$; i.e. that the signal is completely informative. Second, we will assume that $p=0$; i.e. that the signal is completely uninformative. In a later section we will address solutions to the model for intermediate values of $p$ and see that these confirm the intuition from the following two sections wile providing additional comparative statics and monotonicity predictions.

\subsection{A perfect information example: $p=1$}

With $p=1$ the employee observes the firm's type perfectly and therefore there is no role for signalling via contractual form. If firm quality is immediately observable by the employee, there is no information game to be played: the standard Holmstrom (1979) argument can be made and its results applied. Throughout the paper I will focus on separating pure strategy perfect Bayesian equilibria (SPSPBE) of this game. A SPSPBE consists of values $\left\{S_{i}, w_{i}, \beta_{i}\right\}_{i=L, H}$ for each firm's contract offer, an effort level $e$ for the employee and two participation choices for the employee that satisfy each firm's sets of incentive and participation constraints and the employee's incentive and participation constraints. Given that we are initially considering only separating equilibria, it is straightforward to write down the constraints described above. Given that the employee has chosen to remain with the firm until the end, her incentive constraint is

$$
\begin{aligned}
I C_{w} \quad: \quad e=\arg \max _{\varepsilon} S+w+\beta E(z \mid \widehat{z}, S, w, \beta) \varepsilon-\frac{1}{2} \varepsilon^{2} \\
\Rightarrow \quad e=\beta E(z \mid \widehat{z}, S, w, \beta)
\end{aligned}
$$

This form for effort is a modified version of Holmstrom (1979) with an expected firm quality parameter added in. This expectation depends on the signal she observes and the contract she has been offered. In fact, because the signal is perfectly informative, we get

$$
I C_{w}: e=\beta z
$$


This form for $e$ allows for the following simplified versions of the firms' and employee's incentive compatibility constraints (ICs) and individual rationality constraints (IRs):

$$
\begin{aligned}
I C_{w} & : \quad e=\beta z \\
I R_{w} & : \quad w+\frac{1}{2} \beta^{2} z^{2} \geq u \\
I C_{H} & : \quad \beta_{H}\left(1-\beta_{H}\right) z_{H}^{2}-S_{H}-w_{H} \geq \beta(1-\beta) z_{H}^{2}-S-w \\
\forall S & \geq 0, w, \beta \text { s.t.w }+\frac{1}{2} \beta^{2} z_{H}^{2} \geq u \\
I C_{L} & : \quad \beta_{L}\left(1-\beta_{L}\right)-S_{L}-w_{L} \geq \beta(1-\beta)-S-w \\
\forall S & \geq 0, w, \beta \text { s.t.w }+\frac{1}{2} \beta^{2} z_{L}^{2} \geq u \\
I R_{H} & : \beta_{H}\left(1-\beta_{H}\right) z_{H}^{2}-S_{H}-w_{H} \geq 0 \\
I R_{L} & : \quad \beta_{L}\left(1-\beta_{L}\right)-S_{L}-w_{L} \geq 0
\end{aligned}
$$

$I C_{w}$ describes the employee's effort when employed at a firm of type $z$ offering incentives $\beta$. Clearly she works higher when her marginal productivity of effort is higher and when she retains a greater fraction of her output. $I R_{w}$ states that she will only remain at the firm if it offers enough total compensation. Notably, $S$ is nowhere in this constraint. Because the employee can abscond with $S$ the firm cannot use the signing bonus to satisfy her individual rationality constraint after she observes $\widehat{z} . \quad I C_{H}$ and $I C_{L}$ state that out of all compensation packages that satisfy the employee's IR and IC constraints, the ones assigned to each firm must be optimal. These constraints become weaker when we move away from the full information case. Finally, $I R_{H}$ and $I R_{L}$ state that each firm must prefer to operate rather than shutting down. Also note that from here on we are using assumption A5: $z_{L}=1$, which allows $z_{L}$ and $z_{L}^{2}$ to be simply omitted from low type constraints.

For the remainder of the paper display of the ICs and IRs will be in the appendix, but those shown above give a good idea of the basic constraints that will continue throughout the paper.

Proposition 1 When firm quality is perfectly observable, the unique perfect Bayesian equilibrium involves a contract offer from each firm with no signing bonus and efficient incentives: $\beta_{i}=1, w_{i}=\max \left\{0, u-\frac{1}{2} z_{i}^{2}\right\}$, and $S_{i}=0$.

We see that so long as employee reservation utility is not too high, each firm offers the efficient incentive when there is no risk present, $\beta=1$, which is "selling the firm to the employee." Wages are negative, and are higher for low quality firms than high quality firms because employees receive less from owning the firm in the low case. There is no signing bonus. As employee reservation utility rises, the low quality firm might become priced out of the market and cease to operate; eventually, the same would happen to high quality firms.

The perfect information case is useful for highlighting the optimal contracts in a more traditional setting, where firms may differ in productive quality but 
have no incentive to design contracts to signal or hide that quality. We now investigate a situation in which the signal is completely uninformative. In this scenario there may be value to a low quality firm attempting to imitate a high quality firm, and therefore there may be value for a high quality firm to design contracts that distinguish its type.

\subsection{A zero information example: $p=0$}

In this section we investigate the case where $p=0$ so that the signal always reads " $\mathrm{H}$ ". As before, we look for SPSPBEs. Unlike before, however, this is a significant restriction on the set of equilibria we are searching for. There are also potentially mixed strategy equilibria and pooling equilibria that we do not attempt to characterize. This section proceeds by first deriving the set of SPSPBEs and a condition that is necessary and sufficient this set to be non-empty. The intuitive criterion is then applied to reduce this set to its most plausible elements and the reduced set is characterized. I will show that SPSPBEs exist when firms are sufficiently different technologically and have two generic properties. First, signing bonuses are positive at high quality firms but zero at low quality firms. Second, incentive intensity is decreasing in firm quality.

Where the signal is uninformative we can ignore it and write our IRs and ICs as before, but we must make some assumption regarding employee beliefs for off equilibrium path actions. To get the largest possible set of equilibria we can begin by assuming that employees perceive contract offers off the equilibrium path to be from the low type of firm. In order to reduce the set of equilibria later in this section we will adjust that assumption.

Lemma 1 The set of SPSPBEs is defined by the following three constraints

$$
\begin{aligned}
I C_{H} & : \quad \max \left\{0, \beta_{H}\left(1-\beta_{H}\right) z_{H}^{2}-S_{H}-w_{H}\right\} \geq \frac{z_{H}}{\left(2-1 / z_{H}\right)^{2}}-u \\
I C_{L}^{2} & : \quad \max \left\{0, \frac{1}{2}-u\right\} \geq \beta_{H}\left(1-\beta_{H}\right) z_{H}-S_{H}-w_{H} \\
I R_{w} & : \quad w_{H}+\frac{1}{2} \beta_{H}^{2} z_{H}^{2} \geq u
\end{aligned}
$$

These constraints put bounds on $w_{H}$ as we vary $\beta_{H}$ and $S_{H}$. The set of equilibria satisfying these conditions can involve positive values of $S_{H}$ as well as wildly inefficient values of $\beta_{H}$. A positive signing bonus, while not economically inefficient, is clearly not ideal for the firm. That $\beta$ can be rather low is both bad for the high quality firm and economically inefficient. This type of phenomenon is not unusual, as in Spence (1973). Because of the three varying contractual dimensions of $S_{H}, \beta_{H}$ and $w_{H}$, not to mention $z_{H}$, it is difficult to display on a graph just what this equilibrium set looks like, but consider the following inequalities that arise from rearranging equations 1 and 2 and assuming that

$u<\frac{1}{2}$ (an assumption we retain for expositional simplicity for the remainder of 
the section):

$$
\beta_{H}\left(1-\beta_{H}\right) z_{H}-\frac{1}{2}+u \leq w_{H}+S_{H} \leq \beta_{H}\left(1-\beta_{H}\right) z_{H}^{2}-\frac{z_{H}}{\left(2-1 / z_{H}\right)^{2}}+u
$$

These inequalities provide bounds for $\left(w_{H}+S_{H}\right)$ as a function of other equilibrium values of contracting variables and parameters: the wage and the signing bonus are treated equally within these inequalities because both have the same cost for each type of firm. From the employee IR is also the case that $w_{H} \geq u-\frac{1}{2} \beta_{H}^{2} z_{H}^{2}$ so there is a limit to how much a wage can be reduced in favor of a signing bonus but, as we will see in section 4, that the two are interchangeable is unique to the $p=0$ case.

It is not always the case that these inequalities can be mutually satisfied, and if they cannot be then no SPSPBE exists.

Lemma 2 A SPSPBE exists so long as $z_{H} \gtrsim 1.8$

Proof. The gap between the upper bound of $w_{H}+S_{H}$ and its lower bound is maximized at $\beta_{H}=\frac{1}{2}$ for $z_{H}>1$. To see whether a SPSPBE exists we therefore must check that,

$$
\frac{1}{4} z_{H}-\frac{1}{2} \leq \frac{1}{4} z_{H}^{2}-\frac{z_{H}}{\left(2-1 / z_{H}\right)^{2}}
$$

Solving the quartic numerically yields $z_{H} \gtrsim 1.8$.

When there is no signal strength, a separating equilibrium can be maintained so long as the difference in firm productivity is sufficient. If the firms are too similar, the high quality firm would have to sacrifice too much in pay in order to deter imitation by the low quality firm relative to the additional productivity it could receive from the employee for separation to be profitable.

Now, supposing that $z_{H}$ is high enough for a separating equilibrium to exist, it is worth asking just what that equilibrium looks like. The curves defined by inequalities 1 and 2 are quadratic in $\beta$ with peaks at $\beta=\frac{1}{2}$. Because $1<z_{H}$, the LHS of the inequality is a wider quadratic than the RHS. Therefore, when a separating equilibrium exists, the value of $w_{H}+S_{H}$ will be a member of a set that is crescent shaped in $\beta$. $w_{H}$ and $S_{H}$ are not completely interchangeable: throughout this discussion, the employee IR $w_{H} \geq u-\frac{1}{2} \beta^{2} z_{H}^{2}$ has been ignored, but it places a separate limit on how far $w_{H}$ can be reduced in favor of $S_{H}$.

Proposition 2 If any separating pure strategy PBEs exist, then the set of these SPSPBEs has the following generic properties:

$$
\begin{aligned}
& \beta_{H}<1 \\
& S_{H}>0
\end{aligned}
$$


That is, the firm will offer less than efficient incentives and a positive signing bonus. This result follows from a very simple game in which firms can signal their types using a number of contract features and is the first to see practical importance for signing bonuses. This model also highlights that, contrary to intuition and some previous thinking on the topic, we should expect to see weaker incentives at higher productivity firms.

Discussing generic properties of a set of equilibria may not be entirely convincing. After all, perhaps the actual equilibrium we witness in practice is non-generic. In fact, this model only features generic signing bonuses "because they're there." One could imagine all sorts of odd contract features (a liter of lighter fluid on Flag Day, for example) that would also be generic equilibrium contract properties in a model like this. As long as the quantity of contractual feature is continuous, its provision would be generic. This does not mean, of course, that we should expect to see these things. In order to make some prediction as to what we should see, we need to refine this set of equilibria a bit. The most natural refinement is the Intuitive Criterion, due to Cho and Kreps (1987). This criterion states that if some out of equilibrium action is taken that is equilibrium dominated for type $\mathrm{A}$ and not equilibrium dominated ${ }^{9}$ for type B, the employee should assume the deviator is type B.

Applying the intuitive criterion to high-type actions narrows the equilibrium set to as little as one element: the optimal point in the set from the firm's point of view. Therefore, to find this point, we need to solve

$$
\begin{aligned}
\max _{S, w, \beta} \pi & =\beta(1-\beta) z_{H}^{2}-S-w \\
\text { s.t. } w+\frac{1}{2} \beta^{2} z_{H}^{2} & \geq u \\
\frac{1}{2}+S+w & \geq u+\beta(1-\beta) z_{H}
\end{aligned}
$$

Proposition 3 The set of SPSPBEs satisfying the intuitive criterion are given by $\beta_{L}=1, w_{L}=u-\frac{1}{2}, S_{L}=0$ and

$$
\begin{aligned}
\beta_{H} & =\frac{1}{2} \\
w_{H} & =u-S_{H}+\frac{1}{4}\left(z_{H}-2\right) \\
S_{H} & \in\left[0, \frac{1}{8} z_{H}^{2}+\frac{1}{4} z_{H}-\frac{1}{2}\right]
\end{aligned}
$$

Therefore the set of equilibria satisfying the intuitive criterion still generically contains signing bonuses. Because the bonus enters both the high quality firm's objective and the low quality firm's IC in the same way as $w$, the high

\footnotetext{
9 "Equilibrium Dominated" in this setting means that there is no possible belief on the part of the worker regarding the firm's type that would make the action strictly more profitable for the firm as compared to the action specified in equilibrium.
} 
quality firm is indifferent between offering the bonus and not so long as the employee IR does not bind. Generically, it does not. Indifference is not a justification for bonuses: that will come later, but for now we must note that bonuses exist in this setting.

Importantly, $\beta=\frac{1}{2}<1$. This model features higher quality firms, with greater marginal product from employee effort, using lower incentives. employee effort is $e_{H}=\beta_{H} z_{H}=\frac{1}{2} \frac{1}{\phi}>1=\beta_{L}=e_{L}$ so the employee does work harder at the high quality firm, but she receives a smaller share of the resulting product at the margin. The literature on incentive intensity uses two metrics to measure intensity. First, one can consider the fraction of marginal profit or marginal shareholder value captured by the agent as in Jensen and Murphey (1990). The measure here, $\beta$, uses this definition. Second, one can consider, in dollars or utility, the marginal return to effort captured by the agent. In this model the value of $\beta z$ picks up this definition. Importantly, while incentive intensity in the first sense is declining in firm quality, in the second sense it is increasing. Empirically, suppose we believe that larger firms tend to be higher quality. Then the theory suggests that even though CEOs at higher quality firms take home a smaller fraction of marginal product they should still earn high salaries. Indeed, this is exactly what we see.

To summarize, when the employee can only receive information about the firm attempting to hire her via the firm's contract offer, and not from any other signal, there only exist separating equilibria in which high quality firms signal their quality to employees when firm qualities are sufficiently different. When this is the case, however, the resulting separating equilibria feature low quality firms using optimal incentive devises while high quality firms have inefficiently low incentives and offer signing bonuses generically.. When we consider only equilibria satisfying the intuitive criterion, we see that high quality firms typically offer exactly half of the efficient level of incentives, though they still generically offer signing bonuses. This contrasts to the full information case when employees receive perfect signals of firm quality. Not surprisingly, since that case has been analyzed by Holmstrom (1979) and others, both types of firm offer efficient incentives and do not offer signing bonuses.

The preceding two sections should give the reader a taste of how the choice variables and parameters in this model interact to produce results. They also reveal a relationship between information, firm quality and contractual form that has not been identified before. That higher quality firms offer lower incentives than low quality firms as a signal of their quality is both new and counter intuitive. Empirical work and other analyses that assume that signing bonuses are a sign of shady contracting (e.g. Bebchuck and Fried (2004)) or non-arms length bargaining should take note that information, industry and job description can interact in odd ways.

Thus far there has been little positive use for signing bonuses as the cost of a bonus was identical across firms in both the $p=1$ and $p=0$ cases. In the former, a signing bonus is wasted money as it serves no signaling purpose while costing both firms dearly. In the latter it also serves no signaling purpose because low quality firms are never revealed prior to the employee choosing to 
stay with a firm and exerting effort. As we will see, intermediate values of $p$ are a markedly different story.

\section{The full model with $p \in(0,1)$}

When the signal strength is between 0 and 1 the analysis becomes more complicated. As opposed to the no information case studied in section 3.2, low quality firms can only imitate high quality firms with some probability of success less than one. As we will see, this implies a distinction between the signing bonus and the wage that was not precedingly present. The signing bonus was either strictly bad (when $p=1$ ) because it does not enter the employee's IR constraint but does enter the firm's objective function, or was weakly bad (when $p=0$ ) because at best the employee's IR constraint does not bind and the signing bonus can be traded off one for one with the wage.

With an intermediate value of $p$ the signing bonus can play a strictly positive role: suppose $\frac{1}{2}<u$ so that it is inefficient for the low quality firm to operate. It may try to mimic the high quality firm by offering $w_{H}, \beta_{H}$ and hope it is not discovered. If it isn't discovered, the firm can induce higher effort from the employee because the employee believes she is working for a high quality firm and therefore has a higher marginal productivity. Thus the low quality firm can induce high effort and potentially operate profitably, much to the employee's chagrin.

Wages have the same cost to the high and low quality firms and are therefore a weak signalling tool. Incentive intensity is a valuable tool because offering a higher $\beta$ is, in dollars, less costly for the high quality firm: our earlier profit equation, while not correct for intermediate values of $p$, nonetheless sheds light on why.

$$
\pi=\beta_{H}\left(1-\beta_{H}\right) z_{H} z_{i}-u+\frac{1}{2} \beta_{H}^{2} z_{H}^{2}
$$

so the marginal profit from an increase in $\beta_{H}$ is $\left(1-2 \beta_{H}\right) z_{H} z_{i}+\beta_{H} z_{H}^{2}$ which is larger for high quality firms than low. However, the signing bonus can also be a valuable signaling tool: because it is paid prior to the employee observing the signal of firm quality, its cost is different for low and high quality firms. Suppose that the equilibrium high quality contract involves a bonus and a low quality firm attempts to mimic the high quality firm. It must pay the bonus before the employee observes the signal. If the signal is $\widehat{z}=L$ then the employee knows that the firm is low quality and can act accordingly. The employee would either quit, causing the low quality firm to eat the loss of the signing bonus, or would remain at the firm (if $w$ and $\beta$ are high enough) but exert a low amount of effort. This, of course, is even worse given that $u>\frac{1}{2}$ ! The signing bonus is still bad for the high quality firm in that it does not enter into the employee's IR constraint, but there is now a trade-off where before there was none.

It should now be clear why the timing of payments and information was set the way it was, but this model is only a small abstraction from reality. In fact, information is revealed over time, and there are many points in a employee's 
career when she may decide to leave the firm. In practice she would rarely leave immediately after accepting the bonus but the basic intuition of the separation in this model - that stronger firms will be less likely to lose employees early in their careers and therefore are more able to offer bonuses - seems right.

As in the preceding sections we will evaluate separating equilibria, but there are two cases to consider. Either it is inefficient for the low quality firm to operate, $u>\frac{1}{2}$, or it is not, $u \leq \frac{1}{2}$. In the former case the low quality firm must compare imitating the high quality firm to not entering the market and receiving a payoff of 0 . In the latter it compares imitating to its best alternative: $\beta=1, w=u-\frac{1}{2}$ which yields a payoff for the firm of $\frac{1}{2}-u$. The two cases are mathematically very similar so we treat the case where $u>\frac{1}{2}$ here and briefly discuss the alternative case in section 4.2. The only material difference regards the existence of SPSPBEs. In the case where it is inefficient for the low quality firm to operate, an equilibrium always exists which is a very convenient feature. In the alternative case equilibria do not always exist, but the properties of optimal contracts are identical whenever they do.

\subsection{The inefficient operation case: $u>\frac{1}{2}$}

We consider the case in which it is inefficient for the low quality firm to operate but efficient for the high quality firm to operate. We therefore have $\frac{1}{2}<u<$ $\frac{1}{2} z_{H}^{2}$.

Proposition 4 The set of SPSPBEs when signals are imperfect and $\frac{1}{2}<u<$ $\frac{1}{2} z_{H}^{2}$ is given by the following four inequalities

$$
\begin{aligned}
I R_{w} \quad: \quad w+\frac{1}{2} \beta^{2} E(z \mid \widehat{z}, S, w, \beta)^{2} \geq u \\
I C_{H}: \quad \beta_{H}\left(1-\beta_{H}\right) z_{H}^{2}-S_{H}-w_{H} \geq \frac{z_{H}}{\left(2-1 / z_{H}\right)^{2}}-u \\
I C_{L}: \quad 0 \geq-S_{H}+(1-p)\left(\beta_{H}\left(1-\beta_{H}\right) z_{H}-w_{H}\right)+p I\left(\beta_{H}\left(1-\beta_{H}\right)-w_{H}\right) \\
I R_{H} \quad: \quad \beta_{H}\left(1-\beta_{H}\right) z_{H}^{2}-S_{H}-w_{H} \geq 0
\end{aligned}
$$

where $I$ is an indicator taking a value of 1 if $w_{H}+\frac{1}{2} \beta_{H}^{2}>u$ and a value 0 otherwise.

There always exist values of contracting variables that mutually satisfy these constraints:

Proposition 5 A separating pure strategy perfect Bayesian equilibrium exists in the game with intermediate signal precision and employee reservation wage $u>\frac{1}{2}$

Given that equilibria exist, we can characterize the size of the equilibrium set as we vary signal informativeness.

Lemma 3 More informative signals of firm quality weakly expand the set of equilibria 
Proof. Recall that $p$ is the probability that a low type of firm is discovered by the employee via the signal $\widehat{z}$; as $p$ rises the signal becomes more informative. Within the four constraints above we see that $p$ only affects the low firm's incentive compatibility constraint. Taking a derivative of the RHS with respect to $p$ we get

$$
-\left(\beta_{H}\left(1-\beta_{H}\right) z_{H}-w_{H}\right)+I\left(w_{H}+\frac{1}{2} \beta_{H}^{2}>u\right)\left(\beta_{H}\left(1-\beta_{H}\right)-w_{H}\right)
$$

which is more simply stated as

$$
\left\{\begin{array}{c}
w_{H}-\beta_{H}\left(1-\beta_{H}\right) z_{H} \text { when } w_{H}+\frac{1}{2} \beta_{H}^{2} \leq u \\
-\beta_{H}\left(1-\beta_{H}\right)\left(z_{H}-1\right) \text { when } w_{H}+\frac{1}{2} \beta_{H}^{2}>u
\end{array}\right\}
$$

which is negative in either case. A more informative signal, therefore, weakens the low type's IC constraint just as intuition would suggest. The more likely the low quality firm will be discovered by the employee, the less attractive attempting to mimic the high firm will be. Because $p$ does not enter the other two relevant constraints, more informative signals weakly expand the equilibrium set.

Unless the employee's individual rationality constraint binds, the signing bonus and wage can be traded off one for one in the high type of firm's constraints. In the low type's IC constraint, the signing bonus can be traded one for one with the wage when $w_{H}+\frac{1}{2} \beta_{H}^{2} z_{L}^{2}>u$ and can be traded of at a $\frac{1}{1-p}$ ratio when $w_{H}+\frac{1}{2} \beta_{H}^{2} \leq u$. As in the case where $\mathrm{p}=0$ and the signal is completely uninformative, there may be a set of equilibria that contain signing bonuses as an "afterthought": They serve little purpose beyond delivering money to employees.

As before, we can now restrict attention to those equilibria satisfying the Cho Kreps intuitive criterion. This criterion is met so long as the equilibrium contract $\left\{S_{H}, w_{H}, \beta_{H}\right\}$ maximizes the profits of the high quality firm subject to the low type's IC constraint and the employee IR constraint.

Proposition 6 The unique separating pure strategy perfect Bayesian equilibrium satisfying the intuitive criterion when signal strength is not perfectly informative is given by the low quality firm choosing not to operate and the high quality firm setting

$$
\begin{aligned}
\beta_{H}= & \frac{z_{H}-(1-p)}{(2-p) z_{H}-2(1-p)} \\
w_{H}= & u-\frac{1}{2}\left[\frac{z_{H}-(1-p)}{(2-p) z_{H}-2(1-p)}\right]^{2} z_{H}^{2} \\
S_{H}= & (1-p) \frac{z_{H}-(1-p)}{(2-p) z_{H}-2(1-p)} z_{H}\left(1+\frac{z_{H}-(1-p)}{(2-p) z_{H}-2(1-p)}\left(\frac{1}{2} z_{H}-1\right)\right) \\
& -(1-p) u
\end{aligned}
$$


These formulas are complicated which was the reason for the simple examples in sections 3.1 and 3.2, but it is straightforward to sign the relationships between these contract elements and underlying parameters. There are two interesting contract elements, the signing bonus and the performance bonus, and two job/industry parameters, the signal strength and the firm quality dispersion. Each of the four resulting relationships is monotonic and will be derived in turn.

Proposition 7 The incentive intensity offered by the high quality firm is increasing in signal strength and decreasing in firm quality dispersion.

Proof. Taking a derivative of the high type's incentive intensity $\beta_{H}$ with respect to $p$ we get

$$
\frac{\partial}{\partial p} \beta_{H}=\frac{z_{H}^{2}-z_{H}}{\left[(2-p) z_{H}-2(1-p)\right]^{2}}
$$

This value is greater or less than 0 when

$$
z_{H}^{2}-z_{H} \gtreqless 0
$$

Because $z_{H}>1$ we get $\frac{\partial}{\partial p} \beta_{H}>0$. High type incentive intensity is monotonically increasing in signal precision. Taking a derivative of $\beta_{H}$ with respect to $z_{H}$

$$
\frac{\partial}{\partial z_{H}} \beta_{H}=-\frac{p(1-p)}{\left[(2-p) z_{H}-2(1-p)\right]^{2}}<0
$$

High type incentive intensity is monotonically decreasing in firm quality dispersion.

Recall that in sections 3.1 and 3.2 we saw that $\beta_{H}=\frac{1}{2}$ in the no information $(p=0)$ case and $\beta_{H}=1$ in the full information $(p=1)$ case. These values hold here, as they must, but the fact that the relationship is monotonic is new. Higher values of $z_{H}$ imply greater difference between the firms' technologies and we see that high type incentive intensity is decreasing as the technological differences between the firms increase: The more different the firms, the lower the incentive intensity must be for high quality firms!

One might imagine that there is a relationship between the dispersion in firm quality and the precision of information about that quality, i.e. that as $z_{H}$ increases $p$ would increase a well. The limit of $\beta_{H}$ as $z_{H} \rightarrow \infty$ is $\frac{1}{2-p}$. Indeed, if information precision and firm quality are positively related then we may observe roughly constant levels of $\beta_{H}$ across jobs and industries.

Corollary 1 If firm quality dispersion and signal precision are positively related by the formula

$$
z_{H}=\frac{(1-p)(1-2 c)}{1-(2-p) c}, c \geq \frac{1}{2}
$$

then $\beta_{H}$ is constant and equal to $c$. 
Proof. Substituting this value in for $z_{H}$ in equation 5 yields a constant value for $\beta_{H}$.

Empirical estimates of the importance of, for example, information availability for employees on incentive intensity cannot be made without considering other relevant parameters. In this model, that means that firm quality dispersion must be taken into account.

To analyze the size of the optimal signing bonus as information changes, recall that the signing bonus is equal to

$$
S_{H}=(1-p)\left(\beta_{H}\left(1-\beta_{H}\right) z_{H}-w_{H}\right)>0
$$

Then we have the following results

Proposition 8 The signing bonus offered by the high quality firm is decreasing in signal strength and increasing in firm quality dispersion.

Signing bonuses shrink as signal quality increases. As $p \rightarrow 1$, in fact, equation 8 reveals that the optimal signing bonus $S_{H} \rightarrow 0$, which is an equilibrium value of the signing bonus in the full information case. As information becomes more accurate, there is less need for a costly signal of firm quality via the signing bonus and the reduced incentive intensity.

Profit at the high type of firm also increases as signal strength increases: revenue increases as incentives can be adjusted toward the optimal level while the total cost of paying the employee, which equals $u+S$, decreases along with S.

Wrapping up this section we discuss why incentive intensity and the size of the signing bonus move in opposite directions relative to underlying parameters like signal strength and quality dispersion. Both a positive signing bonus and low incentive intensity are costly for the firm, but in each case the cost is lower for the high quality firm. It is surprising that low incentive intensity is a signal of high quality, but in words the story is approximately as follows: "We can offer incentives that cause employees to underwork and we can still earn a profit. That's how productive our technology is!" Only a high quality firm can make that claim. The corresponding claim for signing bonuses is "We are so confident that you'll like what you see after joining the firm that we'll give you pay up front, unconditionally, knowing that you'll stay on." Importantly, the employee IR still binds at the equilibrium described above: the signing bonus is a cost borne by the high quality firm over and above the minimum necessary to attract the low type of employee. However, as the firm raises the signing bonus it can also raise incentive intensity to more efficient levels. The solution to the optimization is interior. 


\subsection{The efficient operation case: $u \leq \frac{1}{2}$}

We briefly consider the case where it is efficient for the low quality firm to operate without attempting to mimic the high quality firm. In this case we consider the same constraints as before, with the exception that the low type of firm's IC once again includes specified low type actions that maximize its profit given that it reveals itself. The solution to this problem is the same as in equation 11 , with $\beta_{L}=1, w_{L}=u-\frac{1}{2}$. The low type of firm certainly will not offer a signing bonus as this does not affect the employee IR but negatively affects the firm's objective.

The optimization problem here is equivalent to the one in section 4.1 with the redefining of $\bar{u}=\frac{1}{2}-u$. The marginal profit relative to $\beta$ does not change with this change in the low firm's incentive compatibility constraint, but $I C_{L}$ is looser, allowing for a smaller signing bonus than before. The comparative statics do not change in this case given that a SPSPBE exists, but the lower value of $u$ will sometimes prevent existence. For any given $p$, nonexistence would occur for values of $z_{H}$ close to 1 (low quality dispersion) but there would exist a $z_{H}^{*}(p)$ such that for any $z_{H} \geq z_{H}^{*}(p)$ SPSPBEs would exist.

\section{Taking theory to the data}

The preceding analysis has uncovered a relationship between parameters describing a particular job or industry, namely the dispersion of firm specific productivity within the industry and quality of information regarding those productivity, and the existence and size of compensation elements like performance incentives and signing bonuses. Surprisingly, within an industry the more productive firms have weaker performance incentives but they offer signing bonuses instead. Furthermore, incentive intensity and the size of the signing bonus move in opposite directions as information improves or firm productivity dispersion changes. It would seem that empiricists should find a negative relationship between these contractual elements, yet it seems very likely that they would instead find a positive relationship.

In fact, the implied negative relationship in this paper is only within one job/industry pair. Across jobs or industries this relationship might reverse. There are three important considerations when taking this model to the data which will be discussed in turn.

\subsection{Empirical implications of censoring}

Low quality firms in section 4.1 do not operate. All firms that would be present in the industry or the data would offer the same incentive pay and the same signing bonus. It may seem unlikely that the condition $u<\frac{1}{2}$ would typically be valid, but consider that industries with a high human capital to physical capital ratio are likely to be the ones where we find signing and performance bonuses in practice, and are also the ones where it is most likely for low quality 
firms to drop out of the data. Additionally, this analysis was done with only one type of employee. In practice we are likely to find assortative matching, with the best employees going to the best firms. In this analysis we must interpret a firm getting employees who are not the best as "dropping out of the data" but in practice they would simply be getting lower quality employees. They would pay the employees less overall, but within their tier the same relationship found in this paper might hold. So long as this is true, the negative relationship between performance and signing bonuses would be true within each tier but across tiers would likely reverse.

\subsection{Two measures of performance pay}

Returning to a previous discussion, there are two distinct concepts for what "incentive intensity" means. In this paper it refers to the fraction of the value of the marginal product retained by the employee. It does not describe the dollar value of the performance bonus, though this is certainly an equally valid definition. In this paper, within one job/industry pair (or job/industry/tier triple if the analysis in section 5.1 is to your liking) the fraction of the value of the marginal product retained by employees is lower for contracts with signing bonuses, but the dollar value of the performance bonus is actually higher when a signing bonus is offered. Taking this to the data, it is necessary to consider the fraction of product retained and not the level of performance pay when evaluating the success of this model.

\section{3 (Un)Hidden action}

The preceding two arguments notwithstanding, it still seems that bonuses of all types go together. The analysis in this paper supports this view so long as one small adjustment is made. There are many situations, in practice, where the employee's actions are not hidden: effort is observable. In this case there is no need for a performance bonus because effort can simply be monitored and mandated. Without the performance bonus there is also no capacity for the signing bonus to signal firm quality because firm quality is irrelevant to a employee who is not receiving a performance bonus: she only cares what she is paid and how hard she is expected to work. Without hidden action (or hidden information of a employee's type, which has been excluded from the model for simplicity but is equally relevant) there is neither a signing nor a performance bonus. In the data, there would be many observations with zeros for these two contractual features. A regression of signing bonus on performance bonus would be strongly positive, but rather than discount the findings of this paper this regression would strongly support them. If the purpose of a signing bonus is as a signal in order to either get better employees or induce higher effort, it must be coupled with performance pay that rewards employees for either quality or effort. 


\section{The "signing loan" v. the signing bonus}

The signing bonus is the antithesis of "pay for performance", a concept many academics and practitioners hold dear. Money is paid to a employee up front and unconditionally, often before the employee has spent a day or week at the firm, and usually within the first month. The employee may then quit the firm and keep the money. While legally the firm is usually entitled to get back a pro-rated portion of the bonus, in practice it would be too costly for the firm to do so. Lawsuits, ill-will and bad press are all likely to be more costly than potentially retrieving the money is worth.

Most arguments in favor of these bonuses confuse justifications for high pay with justifications for signing bonuses, but even the ones that correctly focus on the timing and conditionality of the payment rather than the level miss an important point. Consider an alternative scheme: offer the same cash flows to the employee, but call the signing bonus a "loan", at $0 \%$ interest, to be repaid in equal installments over the course of the employee's first year at the firm. The only legal difference between these two contracts is that if the employee leaves the firm within the first year, the firm can report any unpaid principal to the credit bureaus as a charged off debt. This would negatively impact the employee's life enough to make repaying the pro-rated portion of the bonus optimal. ${ }^{10}$ Arguments that support a particular structure of cash flows that include a signing bonus (e.g. Van Wesep (2008b)) can not in general support the bonus as opposed to this alternative. This paper can.

There is no signaling power in the "signing loan" as it would enter the employee's IR constraint equally for each firm. The signing loan would just be an advance on the wage and could therefore not signal firm quality. Only a bonus which is sunk once paid has that power. That this theory supports signing bonuses as opposed to signing loans is, I believe, a testament to its inherent plausibility. It is worth noting that signing loans are sometimes part of a firm's contract offer to high human capital employees, but these loans are usually in addition to signing bonuses and are explicitly for expenses related to moving or to fund the gap between the end of one job and the start of the next.

\section{Conclusion}

This paper is the first to offer a rationale for signing bonuses, one of the most prevalent features of white collar labor contracts. I show that signing bonuses are an equilibrium contract feature at firms with high hidden quality, as defined by the marginal product of employee effort, and serve as a signal to employees of that quality. As information regarding firm quality is less readily available to employees, the size of signing bonuses offered by high quality firms increases.

\footnotetext{
${ }^{10}$ Consider that this penalty is the only practical one any of us face from non-payment of a debt. If we decline to pay a $\$ 4,000$ debt to Capital One, we will not be sued and collectors will have little recourse. The fact that most people, especially those with higher incomes who are more likely to end up in jobs with signing bonuses, pay their debts suggests that this is a sufficient deterrent.
} 
I argue that industries with high human rather than physical capital probably have murkier information and greater dispersion of quality, which both imply higher signing bonuses. In fact, we may not even see low quality firms in these industries as employees, possessing most of the firm's capital, are able to retain high fractions of their product in equilibrium. In this case, all firms in these industries would offer signing bonuses.

This paper is also the first to show that incentive intensity may be lower at higher quality firms. Within a job/industry pair, lower quality firms reveal themselves and set incentives optimally. Higher quality firms can use different incentives as a signal and it is less expensive to induce too little effort than too much. The size of the optimal incentive intensity at high quality firms depends on the availability of information and the dispersion of firm quality within the job/industry. As information becomes more available, high quality firms can increase incentive intensity without succumbing to imitation from low quality firms. As dispersion of quality grows incentive intensity at high quality firms shrinks, certainly a counter intuitive result. It should be noted, however, that while incentive intensity shrinks, employees are working harder and being paid more! The additional marginal product from being at a better firm outweighs the lower incentives. Firm profit is also increasing in dispersion.

These results suggest that performance bonuses should be lower when signing bonuses are higher, but only within a job and/or industry. Across jobs and industries we should expect to see the opposite relationship. If employee effort and type are observable for firms, both signing and performance bonuses are unnecessary, and their sizes would take values of 0 in the data. When effort (or type) is unobservable, we will often see both bonuses. Therefore a regression of one bonus type on the other would yield signs with different coefficients depending upon whether job/industry fixed effects are included.

Finally, this model justifies the existence of signing bonuses as opposed to signing loans, a justification sorely lacking in colloquial understanding of signing bonuses. While this seems like a minor point, the existence of signing bonuses is a mystery when compared to signing loans, and a story that justifies that existence is necessary. 


\section{References}

1. Almazan, Andres and Javier Suarez (2003). Entrenchment and Severance Pay in Optimal governance Structures, Journal of Finance 2, 519-547

2. Arya, Anil, Hans Frimor and Brian Mittendorf (2003). Pouring Money Down the Drain? How Sunk Investments and Signing Bonuses can Improve Employee Incentives, The B.E. Journal of Economic Analysis and Policy 1, Article 6

3. Bebchuk, Lucien and Jesse Fried (2004). Pay without Performance: The Unfulfilled Promise of Executive Compensation, Cambridge: Harvard University Press

4. Cho, In-Koo and David Kreps (1987). Signaling Games and Stable Equilibria, Quarterly Journal of Economics 2, 179-222

5. Green, Jerry and Nancy Stokey (1983). A Comparison of Tournaments and Contracts, Journal of Political Economy 3, 349-364

6. Holmstrom, Bengt (1979). Moral Hazard and Observability, Bell Journal of Economics 1, 74-91

-(1982). Moral Hazard in Teams, Bell Journal of Economics 2, 324-340

7. Jensen, Michael and Kevin Murphey (1990). Performance Pay and Top Management Incentives, Journal of Political Economy 2, 225-264

8. Lambert, Richard and David Larcker (1985). Golden Parachutes, Executive Decision Making, and Shareholder Wealth, Journal of Accounting and Economics 7, 179-203

9. Lazear, Edward and Sherwin Rosen (1981). Rank-Order Tournaments as Optimum Labor Contracts, Journal of Political Economy 5, 841-864

10. Manso, Gustavo (2008). Motivating Innovation, MIT working paper

11. Milgrom, Paul and John Roberts (1986). Price and Advertising Signals of Product Quality, Journal of Political Economy 4, 796-821

-(1992). Economics, Organization and Management, New Jersey: Prentice Hall

12. Prendergast, Canice (1999). The Provision of Incentives in Firms, Journal of Economic Literature 1, 7-63

13. Van Wesep, Edward D (2008a) Golden Parachutes for Good Behavior, University of North Carolina Working Paper

-(2008b) Quasi-Hyperbolic Discounting and Contract Design, University of North Carolina Working Paper 


\section{Appendix}

\section{Proof of proposition 1.}

If we assume that the firm's IR constraints do not bind, solving the game is straightforward. $I C_{H}$ and $I C_{L}$ allow us to solve for optimal contracts simply with calculus:

$$
\begin{aligned}
\max _{S, w, \beta} \pi & =\beta(1-\beta) z_{i}^{2}-S-w \\
\text { s.t.w }+\frac{1}{2} \beta^{2} z_{i}^{2} & \geq u
\end{aligned}
$$

Clearly $S$ and $w$ are interchangeable in the firm's objective function but only $w$ factors into the IR constraint. Therefore the firm must set $S=0$. The IR constraint should bind so the optimization problem reduces to

$$
\begin{aligned}
& \max _{\beta} \beta(1-\beta) z_{i}^{2}-u+\frac{1}{2} \beta^{2} z_{i}^{2} \\
\Rightarrow & (1-2 \beta) z_{i}^{2}+\beta z_{i}^{2}=0 \\
\Rightarrow & \beta=1, w=u-\frac{1}{2} z_{i}^{2}
\end{aligned}
$$

This result is only valid if the firms' IR constraints are not violated:

$$
\begin{aligned}
I R_{i} & : \quad \beta_{i}\left(1-\beta_{i}\right) z_{i}^{2}-S_{i}-w_{i} \geq 0 \\
& \Rightarrow \frac{1}{2} z_{i}^{2} \geq u
\end{aligned}
$$

Proof of lemma 1. The relevant ICs and IRs when the signal is completely uninformative are:

$$
\begin{aligned}
I C_{w} & : \quad e=\beta E(z \mid S, w, \beta) \\
I R_{w} & : \quad w+\frac{1}{2} \beta^{2} E(z \mid S, w, \beta)^{2} \geq u \\
I C_{H} & : \quad \beta_{H}\left(1-\beta_{H}\right) z_{H}^{2}-S_{H}-w_{H} \geq \beta(1-\beta) z_{H}-S-w \\
\forall S & \geq 0, w, \beta \text { s.t.w }+\frac{1}{2} \beta^{2} \geq u \\
I C_{L}^{1} & : \quad \beta_{L}\left(1-\beta_{L}\right)-S_{L}-w_{L} \geq \beta(1-\beta)-S-w \\
\forall S & \geq 0, w, \beta \text { s.t.w }+\frac{1}{2} \beta^{2} \geq u \\
I C_{L}^{2} & : \beta_{L}\left(1-\beta_{L}\right)-S_{L}-w_{L} \geq \beta_{H}\left(1-\beta_{H}\right) z_{H}-S_{H}-w_{H} \\
I R_{H} & : \quad \beta_{H}\left(1-\beta_{H}\right) z_{H}^{2}-S_{H}-w_{H} \geq 0 \\
I R_{L} & : \quad \beta_{L}\left(1-\beta_{L}\right)-S_{L}-w_{L} \geq 0
\end{aligned}
$$

These constraints are similar to those in section 3.1 with three notable changes. First, the employee's IR and IC now include an expectation of $z$ rather 
than $z$ itself. As $z$ is unobservable to the employee, she must act on the basis of her belief about $z$. Second, the high type of firm now must compare its profit from taking its assigned actions and being correctly perceived as a high quality firm (thereby generating higher effort from the employee and allowing it to pay a lower set wage) or deviating and being perceived as low quality. Third, the low quality firm now has two ICs, the first as before and the second comparing the profit from taking its assigned actions to its profit by offering a contract set out for the high type and being perceived as a high type of firm.

To solve this game we proceed by assuming that the firm IRs do not bind and then solving for the low type's optimal action given that it will be perceived as a low type. Only this contract offer will satisfy constraint $I C_{L}^{1}$. As before in equation 11, the optimal contract is $\beta_{L}=1$ and $w_{L}=u-\frac{1}{2}$ with $S_{L}=0$. This assumes of course that $\frac{1}{2} \geq u$ so that the low firm's IR is not violated. We can also find the best alternative for the high type if it chooses to deviate by solving

$$
\begin{aligned}
\max _{S, w, \beta} \pi & =\beta(1-\beta) z_{H}-S-w \\
\text { s.t.w }+\frac{1}{2} \beta^{2} & \geq u
\end{aligned}
$$

Clearly the firm will set $S=0$, and will let the constraint bind so that $w=u-\frac{1}{2} \beta^{2}$ and the problem becomes

$$
\begin{aligned}
& \max _{\beta} \beta(1-\beta) z_{H}-u+\frac{1}{2} \beta^{2} \\
\Rightarrow \quad & (1-2 \beta) z_{H}+\beta=0 \\
\Rightarrow & \beta=\frac{1}{2-1 / z_{H}}, w=u-\frac{1}{2} \frac{1}{\left(2-1 / z_{H}\right)^{2}}, S=0
\end{aligned}
$$

The firm ICs can be reduced to

$$
\begin{aligned}
I C_{H} & : \max \left\{0, \beta_{H}\left(1-\beta_{H}\right) z_{H}^{2}-S_{H}-w_{H}\right\} \geq \frac{z_{H}}{\left(2-1 / z_{H}\right)^{2}}-u \\
I C_{L}^{2} & : \max \left\{0, \frac{1}{2}-u\right\} \geq \beta_{H}\left(1-\beta_{H}\right) z_{H}-S_{H}-w_{H} \\
I R_{w} & : \quad w_{H}+\frac{1}{2} \beta_{H}^{2} z_{H}^{2} \geq u
\end{aligned}
$$

Proof of proposition 3. The optimization must satisfy the employee's IR and the low type firm's IC. As $S$ and $w$ enter equally into the objective function and the low firm's IC, but only $w$ enters into the employee's IR, we can set $S=0$. So long as the employee IR binds at the optimum, this action does not restrict the set of optima, but we must check this choice later. Now the two constraints become

$$
w \geq \max \left\{u-\frac{1}{2} \beta^{2} z_{H}^{2}, u+\beta(1-\beta) z_{H}-\frac{1}{2}\right\}
$$


To solve this problem, we can assume each constraint binds in turn and assume the other does not. We then can solve for the optimal contract and check whether our assumption was correct. If indeed the other constraint does not bind, then we have a candidate equilibrium. For each candidate equilibrium we then check which makes the firm best off and the that equilibrium is the unique SPSPBE satisfying the intuitive criterion. Let us suppose that the low firm's IC binds so that we have $w=u+\beta(1-\beta) z_{H}-\frac{1}{2}$. Then the objective is

$$
\begin{aligned}
\max _{\beta} \pi & =\beta(1-\beta) z_{H}^{2}-u-\beta(1-\beta) z_{H}+\frac{1}{2} \\
& \Rightarrow(1-2 \beta) z_{H}\left(z_{H}-1\right)=0 \\
& \Rightarrow \beta=\frac{1}{2}, w=u+\frac{1}{4}\left(z_{H}-2\right)
\end{aligned}
$$

Plugging in to the employee IR constraint to make sure it does not bind:

$$
\begin{aligned}
u+\frac{1}{4}\left(z_{H}-2\right)+\frac{1}{8} z_{H} & \geq u \\
& \Rightarrow z_{H} \geq \frac{4}{3}
\end{aligned}
$$

It was shown in equation 4 that separating equilibria exist for values of $z_{H} \gtrsim 1.8$. Inequality 24 above suggests that so long as $z_{H}>\frac{4}{3}$, we can also assume that the employee IR constraint does not bind at the equilibrium satisfying the intuitive criterion, so our initial assumption was correct given that a separating equilibrium exists. If the employee IR binds then the equilibrium satisfying the intuitive criterion is found by

$$
\begin{aligned}
\max _{\beta} \pi & =\beta(1-\beta) z_{H}^{2}-u+\frac{1}{2} \beta^{2} z_{H}^{2} \\
& \Rightarrow(1-\beta) z_{H}^{2}=0 \\
\beta & =1, w=u-\frac{1}{2} z_{H}^{2}
\end{aligned}
$$

At these values the low firm IC becomes

$$
z_{H}^{2} \leq 1
$$

which never holds. Our initial candidate equilibrium is therefore the unique SPSPBE satisfying the intuitive criterion. In this case we had

$$
\begin{aligned}
& \beta_{H}=\frac{1}{2} \\
& w_{H}=u+\frac{1}{4}\left(z_{H}-2\right)
\end{aligned}
$$

Also, because the employee IR does not bind, our earlier decision to set $S=0$ was too restrictive. In fact, any choice of $S$ such that $w=u-S+\frac{1}{4}\left(z_{H}-2\right)$ and $w \geq u-\frac{1}{2} \beta_{H}^{2} z_{H}^{2}=u-\frac{1}{8} z_{H}^{2}$ are equivalent in the eyes of the firm. 
Proof of proposition 4. We search for separating pure strategy perfect Bayesian equilibria as before by writing each firm's IC and IR constraints as well as the employee's IC and IR constraint. These are

$$
\begin{aligned}
I C_{w} & : \quad e=\beta E(z \mid S, w, \beta) \\
I R_{w} & : \quad w+\frac{1}{2} \beta^{2} E(z \mid S, w, \beta)^{2} \geq u \\
I C_{H} & : \quad \beta_{H}\left(1-\beta_{H}\right) z_{H}^{2}-S_{H}-w_{H} \geq \beta(1-\beta) z_{H}-S-w \\
\forall S & \geq 0, w, \beta \quad \text { s.t.w }+\frac{1}{2} \beta^{2} \geq u \\
I C_{L}^{1} & : \quad 0 \geq-S_{H}+(1-p)\left(\beta_{H}\left(1-\beta_{H}\right) z_{H}-w_{H}\right)+p I\left(\beta_{H}\left(1-\beta_{H}\right)-(2690)\right) \\
I R_{H} & : \quad \beta_{H}\left(1-\beta_{H}\right) z_{H}^{2}-S_{H}-w_{H} \geq 0
\end{aligned}
$$

where $I$ is an indicator defined previously to take a value of 1 if $w_{H}+\beta^{2} z_{L}^{2}>0$ and 0 otherwise. The first major change from the set of inequalities in equations 13 to 21 is the addition of an indicator function in the low type's incentive compatibility constraint. Whether the employee remains at the firm when a signal of $\widehat{z}=L$ is received depends on whether the employees payoff at the low firm exceeds $u$. This in turn depends on the contract offer made by the firm prior to the signal being received.

In searching for equilibria we can reuse our simplification of the high type of firm's incentive compatibility constraint from equation 22 to rewrite $I C_{H}: \beta_{H}(1-$ $\left.\beta_{H}\right) z_{H}^{2}-S_{H}-w_{H} \geq \frac{z_{H}}{\left(2-1 / z_{H}\right)^{2}}-u$. Within our range of acceptable values of $u, I C_{H}$ may be either more or less restrictive than $I R_{H}$ so neither can be eliminated. This yields the following constraints

$$
\begin{aligned}
I R_{w} & : \quad w+\frac{1}{2} \beta^{2} E(z \mid \widehat{z}, S, w, \beta)^{2} \geq u \\
I C_{H} & : \quad \beta_{H}\left(1-\beta_{H}\right) z_{H}^{2}-S_{H}-w_{H} \geq \frac{z_{H}}{\left(2-1 / z_{H}\right)^{2}}-u \\
I C_{L} & : \quad 0 \geq-S_{H}+(1-p)\left(\beta_{H}\left(1-\beta_{H}\right) z_{H}-w_{H}\right)+p I\left(\beta_{H}\left(1-\beta_{H}\right)-w_{H}\right) \\
I R_{H} & : \quad \beta_{H}\left(1-\beta_{H}\right) z_{H}^{2}-S_{H}-w_{H} \geq 0
\end{aligned}
$$

Proof of proposition 5. We must compare the firm profit from this contract offer to the highest profit it could attain by offering some other contract and being perceived as a low type and receiving $\frac{z_{H}}{\left(2-1 / z_{H}\right)^{2}}-u>0$. Firm profit is

$$
\begin{aligned}
\pi_{H}= & \beta_{H}\left(1-\beta_{H}\right) z_{H}^{2}-S_{H}-w_{H} \\
= & \beta_{H} z_{H}^{2}-u-S_{H} \\
= & \frac{z_{H}-(1-p)}{(2-p) z_{H}-2(1-p)} z_{H}^{2}-p u \\
& -(1-p) \frac{z_{H}-(1-p)}{(2-p) z_{H}-2(1-p)} z_{H} \\
& \times\left(1+\frac{z_{H}-(1-p)}{(2-p) z_{H}-2(1-p)}\left(\frac{1}{2} z_{H}-1\right)\right)
\end{aligned}
$$


Comparing profit in the proposed equilibrium to profit from the best possible deviation we compare

$$
\begin{aligned}
& \frac{z_{H}-(1-p)}{(2-p) z_{H}-2(1-p)} \\
& \times\left[z_{H}-(1-p)\left(1+\frac{z_{H}-(1-p)}{(2-p) z_{H}-2(1-p)}\left(\frac{1}{2} z_{H}-1\right)\right)\right] \\
& +(1-p) u \\
\gtreqless & \frac{1}{\left(2-1 / z_{H}\right)^{2}}
\end{aligned}
$$

Evaluating at extremes, for $z_{H} \approx 1$ equation 32 reduces to

$$
u \gtreqless \frac{1}{2}
$$

Our assumptions driving this section require that $u>\frac{1}{2}$ so a separating equilibrium exists for $z_{H} \approx 1$. Now consider $z_{H} \approx \infty$. Then we get a value on the RHS of comparison 32 of $\frac{1}{4}$ while the LHS has a limit of infinity. As $z_{H}$ rises the importance of the high firm identifying itself grows: when the employee correctly identifies a firm as a high type, she works harder by exerting effort $e_{H}=\beta_{H} z_{H}$. The higher the value of $z_{H}$, the larger the effect on effort that the employee's belief has. Because an equilibrium exists as the technological difference shrinks to zero, we are assured that as the technological difference rises we can be assured that a separating equilibrium exists.

Proof of proposition 6. The unique contract satisfying the intuitive criterion is found by the following constrained maximization program.

$$
\begin{aligned}
\left\{S_{H}, w_{H}, \beta_{H}\right)= & \arg \max _{S, w, \beta} \pi=\beta(1-\beta) z_{H}^{2}-S-w \\
\text { s.t. } 0 \geq & -S_{H}+(1-p)\left(\beta_{H}\left(1-\beta_{H}\right) z_{H}-w_{H}\right) \\
& +p I\left(\beta_{H}\left(1-\beta_{H}\right)-w_{H}\right) \\
w+\frac{1}{2} \beta^{2} z_{H}^{2} \geq & u
\end{aligned}
$$

Assuming first that $w_{H}+\frac{1}{2} \beta_{H}^{2} \leq u$ so that the employee will quit upon the low type firm being revealed, the low type IC constraint is $0 \geq-S_{H}+$ $(1-p)\left(\beta_{H}\left(1-\beta_{H}\right) z_{H}-w_{H}\right)$. Because the high firm's objective function is decreasing in $S$ and $w$ one for one, and because decreases in $w$ only decrease the RHS of $I C_{L}(1-p)$ times as fast as decreases in $S$, two facts follow. First, $I C_{L}$ binds so that $S_{H}=(1-p)\left(\beta_{H}\left(1-\beta_{H}\right) z_{H}-w_{H}\right)$. Second, $S_{H}$ should be increased and $w_{H}$ decreased until the employee's IR binds: $w_{H}=u-\frac{1}{2} \beta^{2} z_{H}^{2}$. The problem then becomes

$$
\begin{aligned}
\beta_{H}= & \arg \max _{\beta} \pi=\beta(1-\beta) z_{H}^{2}-(1-p)\left(\beta(1-\beta) z_{H}-u-\frac{1}{2} \beta^{2} z_{H}^{2}\right) \\
& -u+\frac{1}{2} \beta^{2} z_{H}^{2}
\end{aligned}
$$


The first order condition for $\beta$ is

$$
0=\left(1-\beta_{H}\right) z_{H}^{2}-(1-p) z_{H}\left[\left(1-2 \beta_{H}\right)+\beta_{H} z_{H}\right]
$$

Proof of proposition 8. Taking a derivative of the signing bonus with respect to signal precision yields

$$
\begin{aligned}
\frac{\partial S_{H}}{\partial p}= & -\left(\beta_{H}\left(1-\beta_{H}\right) z_{H}-w_{H}\right) \\
& +(1-p)\left(\left(1-2 \beta_{H}\right) \beta_{H}^{\prime} z_{H}-w_{H}^{\prime}\right) \\
= & -z_{H}\left(\beta_{H}\left(1-\beta_{H}\right)-w_{H}\right) \\
& -\frac{p(1-p)}{\left[(2-p) z_{H}-2(1-p)\right]^{2}} z_{H}(1-p)\left(\left(1-2 \beta_{H}\right)+\beta_{H} z_{H}\right)
\end{aligned}
$$

The first term is negative (from equation 8) and the second is negative because $z_{H}>1$. Therefore we have $\frac{\partial S_{H}}{\partial p}<0$.

Next we evaluate how the size of the signing bonus depends on $z_{H}$, the ratio of the firms' productivity. From the equation $S_{H}=(1-p)\left(\beta_{H}\left(1-\beta_{H}\right) z_{H}-w_{H}\right)$ we can directly evaluate the effect of $z_{H}$. As $z_{H}$ rises $\beta_{H}$ falls, but because $\beta_{H}>\frac{1}{2}$ the product $\beta_{H}\left(1-\beta_{H}\right)$ rises. The effect on $w_{H}$ as $z_{H}$ rises is found by

$$
\frac{\partial w_{H}}{\partial z_{H}}=-\beta_{H} z_{H}\left[z_{H} \frac{\partial \beta_{H}}{\partial z_{H}}+\beta_{H}\right]
$$

This is less than 0 so long as $z_{H} \frac{\partial \beta_{H}}{\partial z_{H}}+\beta_{H}<0$. To check this we can plug in values from equations 5 and 7 to get

$$
\begin{aligned}
z_{H} \frac{\partial \beta_{H}}{\partial z_{H}}+\beta_{H} & =-z_{H} \frac{p(1-p)}{\left[(2-p) z_{H}-2(1-p)\right]^{2}}+\frac{z_{H}-(1-p)}{(2-p) z_{H}-2(1-p)} \\
& =\frac{-(2-p) z_{H}^{2}+4(1-p) z_{H}-2(1-p)}{\left[(2-p) z_{H}-2(1-p)\right]^{2}}
\end{aligned}
$$

This is less than 0 so long as the numerator is less than 0 . The numerator is decreasing in $z_{H}$ so long as $z_{H}>\frac{1-p}{1-p / 2} \cdot \frac{1-p}{1-p / 2}<1$ so this condition is always satisfied. The numerator takes a value of -2 when $z_{H}=1$ and therefore is always negative. Therefore $w_{H}$ is decreasing in $z_{H}$ and $-w_{H}$ is increasing in $z_{H}$. The signing bonus is increasing $z_{H}$ : as the firms' productivity get increasingly different, the signing bonus grows:

$$
\frac{\partial S_{H}}{\partial z_{H}}>0
$$




$\begin{array}{llllll} & \begin{array}{l}\text { Signing } \\ \text { bonus } \\ \text { size }\end{array} & \begin{array}{l}\text { Incentive } \\ \text { intensity }\end{array} & \begin{array}{l}\text { Quality } \\ \text { observ- } \\ \text { ability }\end{array} & \begin{array}{l}\text { Quality } \\ \text { disper- } \\ \text { sion }\end{array} & \begin{array}{l}\text { Worker } \\ \text { observ- } \\ \text { ability }\end{array} \\ \text { Professor } & 1 & 1 & 5 & 2 & 4 \\ \text { Waiter } & 1 & 2 & 4 & 1 & 5 \\ \text { Start-up } & 5 & 5 & 1 & 5 & 3 \\ \text { Consultant } & 3 & 4 & 3 & 4 & 2 \\ \text { CEO } & 4 & 3 & 2 & 3 & 1\end{array}$

Table 1: Rank-order for each profession in each of four categories with one being the lowest and five being the highest. Signing bonus size and incentive intensity describe a typical contract while quality observability, employee observability and quality dispersion describe the job or industry. 


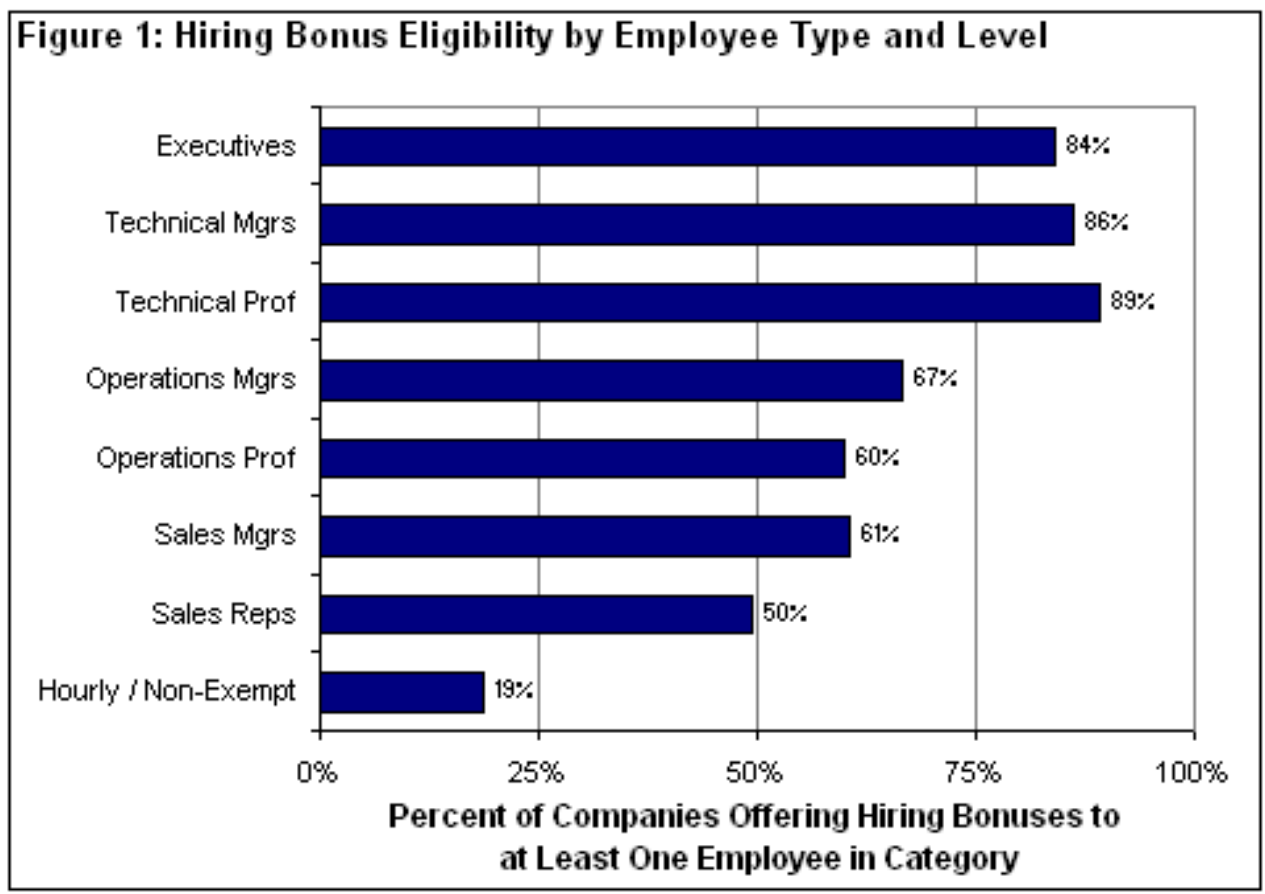

Figure 1: Hiring bonus availability differs by job class. Jobs involving greater human capital are more often associated with signing bonuses. 


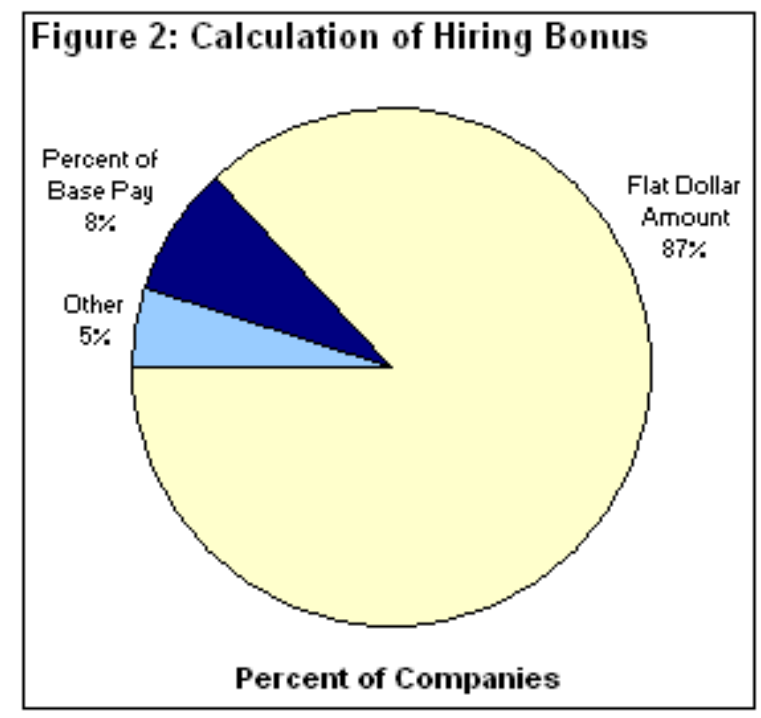

Figure 2: Signing bonuses are typically set independantly from other pay components. 


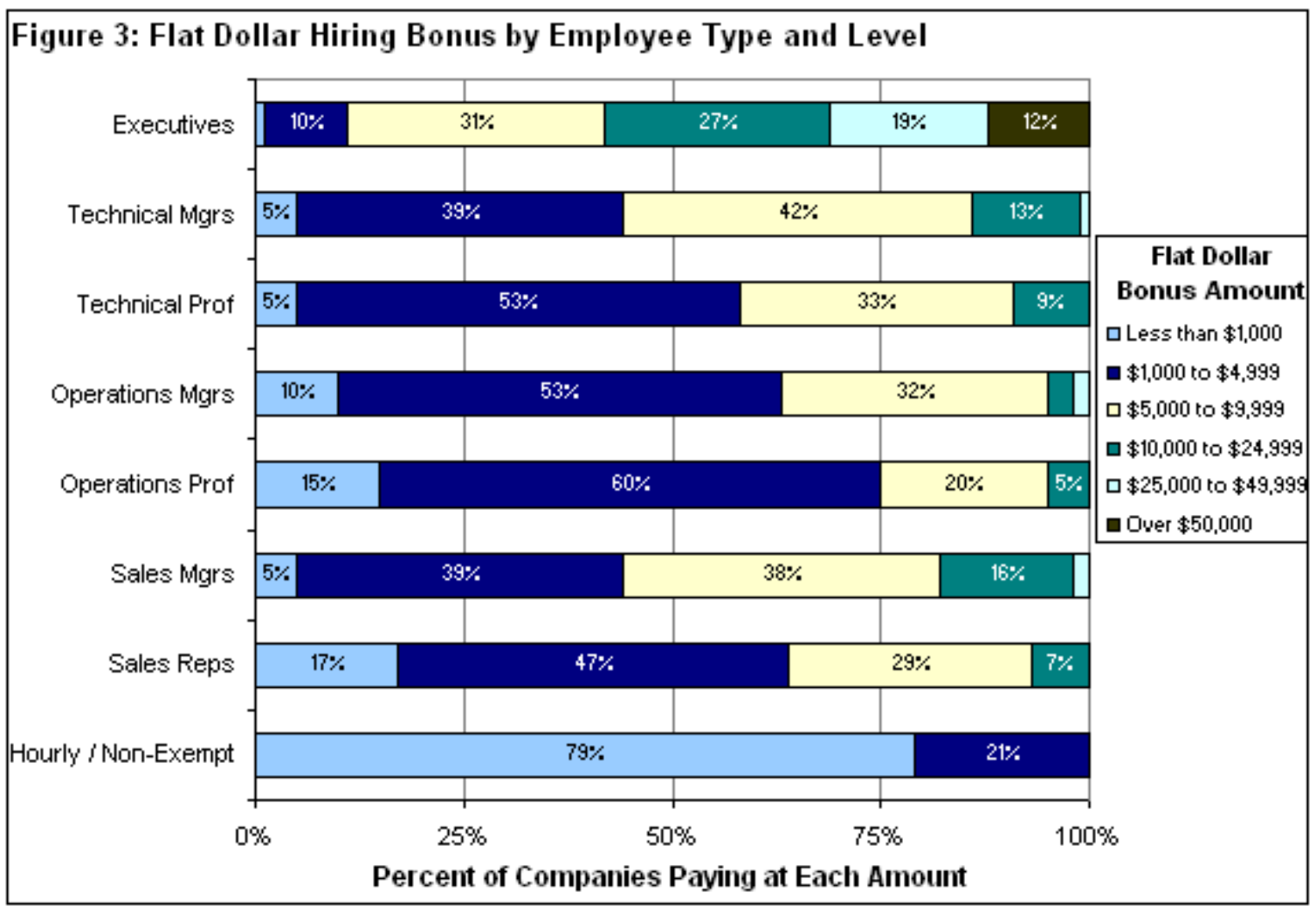

Figure 3: The size of signing bonuses differ by job class. With the exception of sales managers, larger signing bonuses are given to employees in jobs requiring greater human capital. 


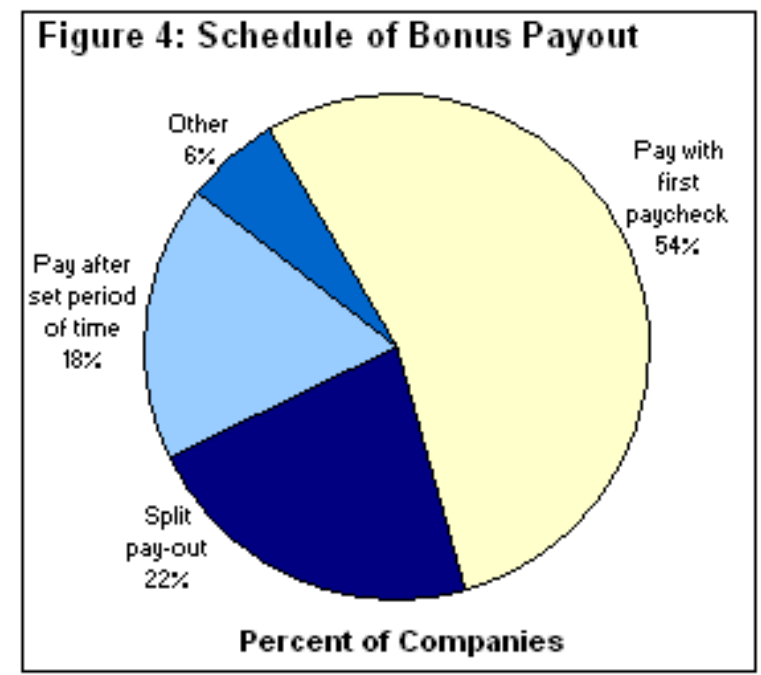

Figure 4: A majority of signing bonuses are given at or before the first paycheck.

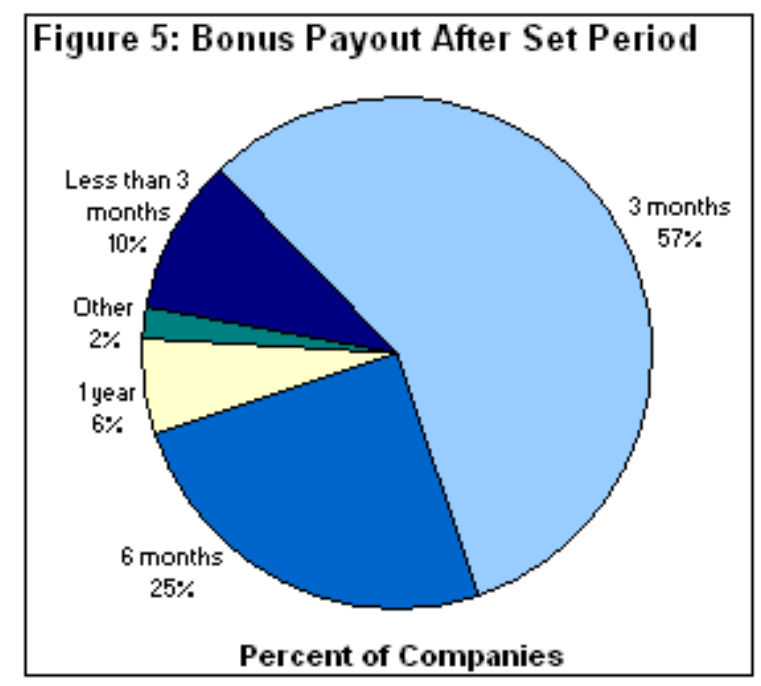

Figure 5: Bonuses delivered at a date after the first paycheck are typically given within one or two quarters of the employee's start date. 


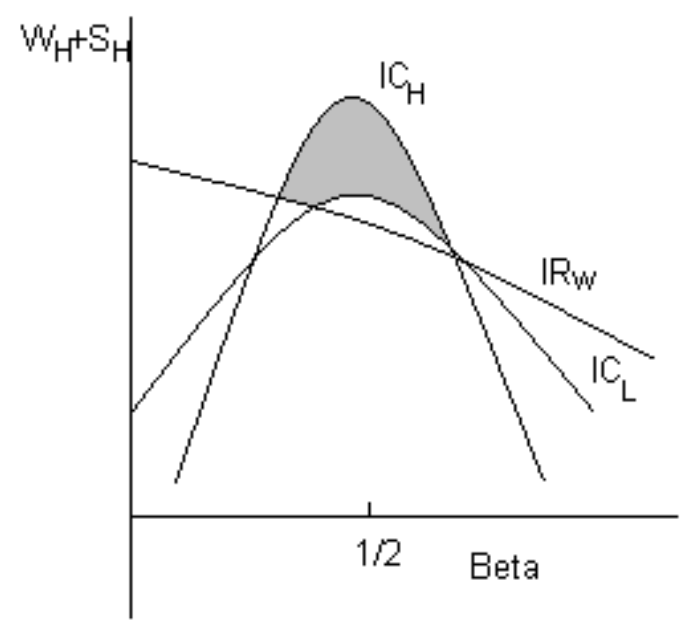

Figure 6: The set of separating pure strategy perfect Bayesian equilibria. So long as a SPSPBE eqists, the set of such equilibria takes the crescent shape shown with the top boundary defined by the high quality firm's IC and the bottom boundary defined by the low quality firm's IC. In the figure, $w_{H}$ and $S_{H}$ are treated eaually, but the level of $I R_{w}$ depends on $w_{H}$ only. As $S_{H}$ increases and $w_{H}$ decreases, maintaining a constant value on the $w_{H}+S_{H}$ axis in the figure, the curve representing $I R_{w}$ increases. 